Luiz Eduardo.

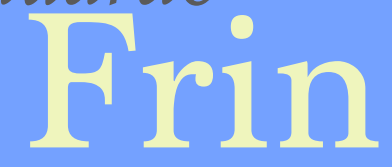

Alexandre

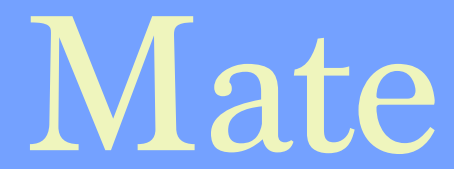

\title{
A atividade teatral paulistana no século XXI e o conceito de "forma de produção"
}

Resumo: A partir da apreciação do trabalho de duas companhias teatrais da cidade de São Paulo: a Cia. Livre e a Cia. Teatro Balagan, propõe-se o conceito de "forma de produção", contextualizado historicamente e determinante na atividade do chamado Movimento de Teatro Grupo Paulistano.

Palavras-chave: Forma de produção; teatro de grupo; criação colaborativa. 


\section{A atixidade teatral paulistang no século XXI e o conceito de "forma de produçãa"}

LUIZ EDUARDO FRIN ${ }^{29}$

ALEXANDRE MATE ${ }^{30}$

\section{A CIA. TEATRO BALAGAN E O ESPETÁCULO EM CONSTRUÇÃO: CABRAS-CABEÇAS QUE VOAM, CABEÇAS QUE ROLAM}

A Cia. Teatro Balagan, sediada em São Paulo e dirigida por Maria Thais, realizou no mês de novembro de 2015 pré-estreias de seu trabalho: Cabras: cabeças que voam, cabeças que rolam. O projeto no qual se inserem essas apresentações e que prevê a realização de temporada do espetáculo a partir do início de 2016 iniciou-se em 2013 e já teve versões preliminares apresentadas em diferentes datas e locais ${ }^{3132}$. Aliás, o compartilhar com o público do que é denominado de "espetáculo-protótipo" tornou-se elemento importante no trabalho do grupo, que estreou o seu primeiro

\footnotetext{
${ }^{29}$ Mestre e doutorando pelo Instituto de Artes da Unesp. Orientado pelo Prof. Dr. Alexandre Mate.

30 Professor Doutor do Instituto de Artes da Unesp

${ }^{31}$ A ficha técnica das versões apresentadas trouxe as seguintes informações: direção de Maria Thais; atores-criadores- André Moreira, Deborah Penafiel, Flávia Teixeira, Gisele Petty, Gustavo Xella, Jhonny Muñoz, Leonardo Antunes, Maurício Schneider, Natacha Dias, Val Ribeiro, Wellington Campos e Ana Chiesa Yokohama; texto de Luís Alberto de Abreu com dramaturgia do próprio e de Maria Thais; assistência de direção de Murilo de Paula; cenografia e figurinos de Márcio Medina com assistência de Marita Prado; cenotécnicos - Cesar Rezende, Clau Calaca e Wanderley Wagner da Silva; bonecos - Helô Cardoso e Eduardo Caiuby Novaes; preparação musical de Alício Amaral; estagiário - Felipe Boquimpani ; design e ilustrações de Pedro Matallo e produção de Géssica Arjona (CIA. TEATRO BALAGAN, 2015, p. 5).

32 O espetáculo em versão "final" estreou para o público em geral da capital paulistana em 22 de janeiro de 2016 no Centro Cultural São Paulo.
} 
espetáculo em 1999, como consta no texto do programa dessas apresentações preliminares:

A construção de um "espetáculo-protótipo" é uma dinâmica explorada anteriormente na criação de Prometheus - a tragédia do fogo ${ }^{33}$ e tem por objetivo lançar os materiais em espaços distintos para que se observe a flexibilidade e extensão da linguagem, possibilitando que dramaturgia e escritura espetacular se revelem no embate entre as vozes do texto, do ator, do espaço, da música, dos objetos etc.

O espetáculo é, seguramente, o que desconhecemos e encená-lo e nossa maneira de conhecê-lo. (CIA. TEATRO BALAGAN, 2015, p. 3).

Eixo central do trabalho da Balagan e que de certa forma interliga os seus espetáculos é a pesquisa do conceito que a Companhia define como "inumano". Interessa ao grupo a representação da realidade material que se relaciona com a humanidade mas que não é exclusivamente premida por ela (CIA. TEATRO BALAGAN, [20--?]a, on-line). Em Cabras - cabeças que voam, cabeças que rolam, esse "inumano" aflora pela materialização cênica de animais e de objetos relacionados ao cangaço no Nordeste brasileiro. Em cena, atores e atrizes representam homens e mulheres e, também, objetos e animais como a faca, a bala, o cachorro, a cabra, inseridos em um contexto mitológico de conflito, de guerra.

O texto do espetáculo é constituído por crônicas escritas por Luís Alberto de Abreu em processo no qual houve o constante diálogo com a diretora Maria Thais e com os atores e atrizes da Companhia que, por

${ }^{33}$ Espetáculo do repertório da Cia. Teatro Balagan que estreou em outubro de 2011 (CIA. TEATRO BALAGAN, [20--?]b, on-line). 
intermédio de estudos cênicos, nos quais as propostas de Abreu eram representadas, experimentavam e influenciavam a criação.

Após a criação dos textos, os estudos cênicos continuaram insistentemente com o objetivo de que a estrutura do espetacular fosse encontrada. Foi preciso descobrir qual seria a sequência dos textos apresentados, quais se uniriam e em qual ordem para se formar estruturas intermediárias. Como seria a divisão da voz narrativa entre os atores e atrizes e como essa voz emergiria de seus intérpretes. Quais seriam os elementos de encenação - coreografias, desenhos cênicos, músicas, figurinos, iluminação, entre tantos outros, que seriam e como seriam utilizados. Enfim, como esse "embate" entre humano e "inumano" encontraria sua forma.

Inseria-se nesse processo o constante treinamento do grupo, fundamentado, prioritariamente, em duas vertentes. Por um lado, o grupo dedicou-se a apreensão de técnicas relacionadas ao escopo temático do projeto, como o tocar da rabeca e do pandeiro, assim como o aprendizado e a prática de danças e canções tradicionais nordestinas. Por outro lado, a Companhia manteve uma rotina de preparação inspirada em técnicas de artes-marciais orientais.

Aos poucos, então, uma estrutura espetacular foi criada em um processo de constante troca de experiências entre os integrantes do grupo e, também, da Companhia com o público das apresentações do "espetáculo-protótipo". Uma estrutura fragmentada, composta de partes que se justapõem, da mesma maneira que se imbricam tanto as danças e as músicas de tradição popular brasileira, mais especificamente, as nordestinas, com procedimentos cênicos que primam pelo formalismo corporal e cênico, de certa forma, relacionados a experiências teatrais realizadas mundo afora nos séculos $X X$ e $X X I$, assim como a utilização de imagens que causam 
impacto visual e que carregam fortes expedientes simbólicos. Simbolismo perceptível em expedientes cênicos e também, de maneira muito intensa, nos figurinos e na cenografia, cuja equipe de criação foi liderada por Márcio Medina.

Da mesma maneira, é possível verificar que o espetáculo comporta, mescla e relaciona características específicas de cada um de seus realizadores. A utilização da narração em cena em perspectiva da cultura popular brasileira, que é uma das características da dramaturgia desenvolvida por Luís Alberto de Abreu, ganhou forma por intermédio de representações fortemente alicerçadas em expedientes corporais dos atores e das atrizes - o que relaciona a encenação com pressupostos do encenador russo V. E. Meierhold, objeto de profundo estudo da diretora Maria Thais e apresentado por ela própria como seu "mestre imaginário" (THAIS, 2009, p. 1).

No início do século XX, V. E. Meierhold afastou-se do naturalismo, nos moldes propostos por Constantin Stanislavski desenvolvido no Teatro de Arte de Moscou, para propor um teatro de convenções, apoiado no formalismo e constituído, basicamente, sobre dois eixos principais. $\bigcirc$ primeiro é o teatro popular, de feira, com elementos tradicionais e populares da cena e que funcionam como catalisadores da acessibilidade do público à obra, como o humor, a música, a dança, a improvisação e as habilidades circenses. Esses eram elementos centrais de grupos que durante séculos deambularam pela Europa e se apresentavam em lugares públicos e constituíram a chamada Commedia dell'Arte, privilegiada por Meierhold "[...] como matéria de estudo teórico e prático" (PICON-VALLIN, 2013, p. 22). O outro eixo é o da experimentação formalista que se espalhou a partir do início do século $\mathrm{XX}$, associados aos movimentos artísticos europeus de 
vanguarda. No teatro, essa priorização formal teve entre os seus destaques os nomes de: "[...] Georg Fuchs, Adolphe Appia e Edward Gordon Craig, cujos escritos Meirhold leu atentamente" (PICON-VALLIN, 2013, p. 17).

Meierhold foi um dos principais atores do Teatro de Arte de Moscou e, embora tenha se tornado um homem total de teatro, a preocupação com o desenvolvimento da arte do ator foi elemento central de suas pesquisas e determinante na constituição de suas proposições estéticas de encenação, como escreveu a própria Maria Thais:

Quando analisamos o cotidiano do Estúdio V. E. Meierhold, não descrevemos uma escola de teatro com um método de formação do ator desvinculado de um projeto cênico. Observamos, sim, qual o conceito de encenação que emerge dos procedimentos técnicos propostos para o comediante (2009, p. 5).

Ao se acompanhar as atividades da preparação de Cabras - cabeças que voam, cabeças que rolam na sede da Companhia, a Casa Balagan, localizada no bairro da Barra Funda em São Paulo, constatou-se que esse ideal de realização cênica ancorada em processos atorais de representação é o principal elemento estruturador do trabalho do grupo.

De certa forma, as imbricações das influências, de certo modo, gerais, dos criadores nas proposições estéticas que emergem do trabalho, são facilmente perceptíveis. A narração, a absorção de preceitos populares e ancestrais a partir de um olhar do século XXI, a mistura da cultura popular brasileira com procedimentos teatrais relacionados aos movimentos europeus de vanguarda artística, a utilização de técnicas de treinamento e de proposições estéticas de origens orientais, a aposta em criação cenográfica e de figurinos que mescla funcionalidade, simbolismo e impacto 
visual, são expedientes que emergem claramente do espetáculo (ainda, em novembro de 2015, em construção). Mas, o que precisa ser ressaltado para atestar o compromisso do grupo com um fazer teatral que se preocupa em relacionar diversas e diferentes vozes de modo a produzir embates que resultem em criação, é que esse afloramento das contribuições individuais que são transformados em criação coletiva de encenação se mostra, contundentemente, também nos detalhes.

Isso se dá, por exemplo, quando a atriz Gisele Petty estrutura uma de suas participações no espetáculo em movimentações que remetem à dança flamenca, elemento importante de sua formação. Ou quando boa parte de uma das crônicas escritas por Abreu e que, portanto, são premidas do universo do cangaço nordestino brasileiro, são narradas pelo ator Jhonny Muñoz em sua língua natal, o espanhol. E assim, mesmo em um espetáculo repleto de momentos corais (musicais, de narração, de dança e de movimentação cênica), é possível, o tempo todo, presenciar individualidades que se destacam criativamente e que se fortalecem e se potencializam no coletivo.

A CIA. LIVRE E O ESPETÁCULO MARIA QUE VIROU JONAS OU A FORÇA DA IMAGINAÇÃO

mais recente trabalho produzido pela, também paulistana, Cia. Livre, Maria que virou Jonas ou a força da imaginação ${ }^{34}$, estreou em 19 de

\footnotetext{
${ }^{34} \mathrm{O}$ espetáculo tem direção geral e encenação de Cibele Forjaz; direção de movimento de Lu Favoreto; assistência de direção de Artur Abe; textos de Cássio Pires e da Cia. Livre; atuação de Lúcia Romano e Edgar Castro; cenografia de Márcio Medina; figurinos de Fabio Namatame; visagismo de Eliseu Cabral, direção de vídeo de Lucas Brandão; direção musical de Lincoln Antonio; iluminação de Cibele Forjaz e Rafael Souza Lopes; sonoplastia e música ao vivo de Pepê Mata Machado; preparação vocal de Andrea Drigo; direção de cena de Dani Colazante e
} 
fevereiro de 2015. O espetáculo, dirigido por Cibele Forjaz, em menos de um ano já fez duas temporadas na cidade de São Paulo, além de já ter se apresentado em festivais e mostras de teatro.

Com o espetáculo, a Companhia se dispôs a pesquisar o tema da transexualidade nos dias atuais. Seu ponto de partida foi o ensaio $n^{\circ} \mathrm{XXI}$ : $\mathrm{Da}$ força da imaginação, do filósofo francês do século XVI, Michel de Montaigne. Nele, o autor narra a história de uma menina, Marie German, que, ao saltar sobre um buraco, vê o seu corpo passar por uma transformação com o afloramento de um órgão sexual masculino (MONTAIGNE, 1987). A partir daquele episódio, Marie é considerada e aceita socialmente como um menino.

Em Maria que virou Jonas ou a força da imaginação, o público acompanha um espetáculo constituído por elementos diversos de teatralidade e que são provenientes das formações, das pesquisas e das proposições dos integrantes da Cia. Livre. Logo no início, os espectadores são recebidos por duas personagens que se apresentam como transexuais e que se conhecem, naquele exato momento, por intermédio de um site de relacionamentos na internet. As personagens são a atriz/ator Neo Maria, criação da atriz Lúcia Romano, e o ator/atriz Jonas Couto, criação de Edgar Castro. A cena na qual as personagens se conhecem e são apresentadas ao público estabelece o jogo entre ficção e realidade que será mantido durante todo o espetáculo e comporta muitos elementos de performance - que, segundo Cohen (1989), não exclui a representação, mas, a mantém em terreno incerto, no qual as convenções advindas do afastamento psicológico da obra estética, que determinam que o artista não é a personagem e o

Jamile Valente; direção de produção da estreia de Marlene Salgado e direção de produção da Cia. Livre de Laura Salerno (ROMANO (org.), 2015, p. 102). 
público é, prioritariamente, espectador, são questionadas no sentido de propor que artistas e público "entrem" na obra em experiência de vivência ritual (COHEN, 1989, p. 115-122).

O eixo central do espetáculo é o texto teatral constituído principalmente sobre preceitos dramáticos pelo dramaturgo Cássio Pires. Nessa peça, há duas personagens: Ela e Ele, e o que define qual personagem será interpretada por Neo Maria e Jonas Couto é um sorteio realizado com a participação do público. Entretanto, assim como na recepção inicial do público e no sorteio de qual interprete representará qual personagem, há, no decorrer do espetáculo, inúmeros momentos nos quais Lúcia Romano, Edgar Castro e o musicista Pepê Mata Machado, responsável pela sonoplastia e que fica o tempo todo em cena, interferem e, de certa forma, criam contrapontos à dramaturgia de Cássio Pires - interferências feitas por meio de uma série de expedientes como relatos e canções (composições musicais de Lincoln Antônio para letras de Lúcia Romano, Edgar Castro, Cássio Pires e Judith Teixeira). Momentos que muitas vezes receberam acabamento do próprio dramaturgo, mas que foram gerados pelos integrantes da Companhia no decorrer do processo de preparação do espetáculo. As projeções audiovisuais sob a responsabilidade de Lucas Brandão, a cenografia de Márcio Medina (o mesmo da Cia. Balagan), e os figurinos de Fábio Natame também contribuem para que o espetáculo seja evidenciado por intermédio de uma série de sobreposições de procedimentos estéticos. 


\section{AFINIDADES}

Ao apresentar, mesmo que de modo sucinto, os dois espetáculos mais recentes da Cia. Livre e da Cia. Teatro Balagan, evidencia-se que, embora se trate de duas companhias que evidentemente carregam muitas diferenças entre si, há um ponto nevrálgico que possibilita a associação do trabalho das duas, uma com a outra, e, também, com procedimentos de inúmeros grupos, companhias e coletivos teatrais paulistanos.

Cabras - cabeças que voam, cabeças que rolam, e Maria que virou Jonas ou a força da imaginação são espetáculos que possuem unidade, mas não a que é entendida nos moldes de encenação desenvolvidos principalmente a partir de finais do século XIX e durante todo o século XX, contexto no qual a figura do encenador era central e responsável pela homogeneidade estética do espetáculo. Nesse sentido, a encenação teatral tem como principal responsabilidade a de eliminar as arestas provenientes da contribuição de diversos artistas de diferentes modalidades artísticas para que, mesmo em contextos mais simbólicos e de múltiplas possibilidades de interpretação, uma estrutura unificada se estabeleça (ROUBINE, 1998). Por outro lado, houve também, principalmente a partir de meados do século XX, inúmeras proposições teatrais completamente opostas, na qual se combatia justamente essa ideia de unidade e se apostava justamente na ausência da proposição de estruturas unificadoras de percepção (LEHMANN, 2007).

Maria Thais e Cibele Forjaz são encenadoras de grande potencial comprovado e premiado. Grande parte da contundência de seus trabalhos se dá por conseguirem, como verificado no acompanhamento de seus trabalhos, cada uma a seu modo - e muitas vezes com premissas diametralmente opostas -, a confluência das diversas contribuições dos 
artistas com os quais trabalham. Congraçamento que ocorre de modo que as diferenças entre os integrantes dos coletivos que dirigem não se anulem em prol de uma unidade idealizada e rígida a ser alcançada. Eventuais arestas não são necessariamente eliminadas, mas, muitas vezes, ressaltadas e transformadas em elementos de forte impacto cênico. Da mesma maneira, que os espetáculos da Cia. Livre e da Cia. Teatro Balagan estão longe de serem espetáculos premidos pela descontextualização e pela ausência da proposição de mecanismos organizados para a percepção do público.

A Cia. Teatro Balagan lançou seu primeiro trabalho em 1999; a Cia. Livre foi estruturada no mesmo ano e estreou seu primeiro espetáculo em 2000. Desse modo, inserem-se no contexto de um grande número de companhias, grupos e coletivos teatrais paulistanos que permanecem em atividade continuada. Em 2015, segundo Álvaro Machado, são mais de duzentas associações teatrais que, em atividade há mais de dez anos na cidade de São Paulo, produzem espetáculos, organizam seminários, debates e cursos, além de editarem e lançarem publicações como livros e revistas.

Sob o prisma da organização da produção, muitos desses coletivos paulistanos, como a Cia. Livre e a Balagan, trabalham em regime colaborativo - tanto artístico, quanto material -, e estruturam-se a partir de hierarquia horizontal. Assim, cada integrante é instigado a ter participação ativa tanto na função que exerce, especificamente, no grupo, quanto em outras áreas do espetáculo e da administração do coletivo de trabalho. Então, a estrutura funcional é mantida, mas, no tocante a hierarquia, buscase um nivelamento nas relações de poder entre os responsáveis por cada função.

Desse modo, o resultado estético alcançado, como mencionado nos exemplos apresentados aqui, nos quais a unidade que se verifica é 
alcançada, mesmo que paradoxalmente, pela fragmentação, pelo hibridismo, por sobreposições de estilos e influências individuais de cada participante do processo, é proveniente da maneira como esses grupos se organizam para a produção: pela "forma de produção" desses coletivos. "Forma" pelo fato de ser buscada, constituída, muitas vezes em processo de tentativa e erro, pela confluência de experiências de indivíduos que se associaram livremente para o trabalho, em contexto sociocultural específico. "Forma" de acordo com as reflexões de Fayga Ostrower:

A natureza criativa do homem se elabora no contexto cultural. [...] No indivíduo confrontam-se, por assim dizer, dois polos de uma mesma relação: a sua criatividade que representa as potencialidades de um ser único, e sua criação que será a realização dessas potencialidades já dentro do quadro de determinada cultura. [...] criar corresponde a um formar, um dar forma a alguma coisa. Em qualquer tipo de realização são envolvidos princípios de forma, no sentido amplo em que aqui é compreendida a forma, isto é, como uma estruturação (2013, p. 5).

E ainda, na mesma obra:

Formar, importa em transformar. Todo processo de elaboração e desenvolvimento abrange um processo dinâmico de transformação, em que a matéria, que orienta a ação criativa, é transformada pela mesma ação (p. 51).

Ao se buscar entender como esse processo se disseminou pelos grupos paulistanos, como essa "forma de produção" se estruturou, um percurso histórico se evidencia, justamente, a partir dos alicerces que Eric Hobsbawm defende para que uma estrutura analítica de compreensão do 
presente, e até ilações sobre o futuro - a partir da interpretação do passado, seja estabelecida. Estrutura que:

[...] deve estar baseada no único elemento observável e objetivo de mudança direcional nos assuntos humanos, independente de nossos desejos subjetivos ou contemporâneos e juízos de valor, isto é, a capacidade persistente e crescente da espécie humana de controlar as forças de natureza por meio do trabalho manual e mental, da tecnologia e da organização da produção (HOBSBAWM, 2014, p. 53).

Desse modo, a organização de grupos de maneira colaborativa, com hierarquia horizontal, a partir da livre organização de indivíduos para o trabalho, sugere que esse percurso histórico de reflexão deva se iniciar no Brasil em meados dos anos 1970.

\section{O PROCESSO HISTÓRICO}

Em 15 de março de 1974, o general Ernesto Geisel tomou posse como presidente do Brasil (GASPARI, 2014a). Completava-se dez anos da ditadura civil-militar no País e vivia-se, há mais de cinco anos, sob o Ato Institucional mais hostil do Regime - o Al-5 -, que:

[...] significou a quebra da legalidade imposta pelo próprio regime; dava poderes quase ilimitados ao presidente da República, por exemplo, para legislar por decreto, suspender direitos políticos dos cidadãos, cassar mandatos eletivos, suspender o habeas corpus em crimes contra a segurança nacional, julgar crimes políticos em tribunais militares, demitir ou aposentar juízes e outros funcionários públicos (RIDENTI in REIS; RIDENTI; MOTTA (orgs.), 2014, p. 36). 
Com a ascensão de Geisel, iniciava-se, então, um período controverso e contraditório que só iria terminar onze anos mais tarde, com o fim do mandato de seu sucessor, o general João Baptista de Oliveira Figueiredo.

Sob o comando de Geisel, sucedido por Figueiredo, foram postas em prática, primeiro, a chamada "distensão lenta, gradual e segura" e, posteriormente, a "abertura política". Assim, evidenciou-se a uma política de Estado que a despeito de ainda torturar, assassinar e utilizar métodos como a censura às manifestações culturais e à imprensa, teve por principal objetivo a retirada dos militares do comando sem que fossem abaladas as estruturas conservadoras (associadas principalmente ao capital, ao sistema financeiro internacional e à agricultura latifundiária) às quais o Regime se associava. A retirada feita nesses moldes permitiu que crimes cometidos pelas forças do Estado na repressão às forças contrárias à ditadura não fossem apurados e devidamente responsabilizados (GASPARI, 2014a; 2014b).

O processo foi provocado por diversos motivos que fizeram com que Geisel constatasse que o Regime não teria forças para continuar (GASPARI, 2014a, p. 13-14). Dentre esses, inseriram-se os econômicos relacionados ao esgotamento do chamado "Milagre Brasileiro", modelo que, amparado pela forte intervenção do Estado na economia e ancorado na industrialização, sustentou o crescimento constante e pungente do Produto Interno Bruto do Brasil até que dificuldades internacionais, prioritariamente ligadas ao aumento do preço do petróleo, acabassem com essa pungência. Somam-se aos motivos econômicos, os políticos relacionados às lutas pelo poder que envolvia integrantes das forças armadas e alguns aliados. Também, não se pode deixar de mencionar a reação de importantes setores da sociedade civil, alguns que inclusive apoiaram inicialmente o regime, aos arbítrios cometidos pelos aparelhos da ditadura. 
No que diz respeito às reações da sociedade civil, uma plêiade de autores aponta que os meados de 1970 apresentaram uma "novidade" nos movimentos sociais brasileiros. Dentre esses autores, aqui, se destacam os nomes de Marcelo Ridenti (2014) e Marco Antônio Perruso (2009) que apontam o deslocamento, no período, de posições de luta relacionadas, de certa forma, ao pensamento marxista clássico e ao Partido Comunista Brasileiro, para posições mais pontais - práticas -, ligadas diretamente aos movimentos sociais. Ao invés de genericamente lutar para transformar o Estado, passou-se a valorizar a sociedade civil como instrumento de mudança (PERRUSO, 2009, p. 18).

Gaspari ressalta a combatividade dos jovens em meados de 1970 e aponta a dificuldade do Regime em entender e combater as suas "novas" motivações e posições. Para o autor: "Era a ditadura que tinha medo deles, não eles dela". (GASPARI, 2014b, p. 323).

No tocante à atividade teatral, os anos de 1970 constituíram período no qual houve o desmantelamento ou a descontinuação, muito devido à repressão do Estado, das atividades de importantes grupos da cena teatral paulistana que tiveram nos anos 1960 o apogeu de suas produções, como foram os casos do Teatro de Arena e do Teatro Oficina. Por outro lado, novos grupos, com ideais renovados, surgiram em todo o País. Como escreveu Silvia Fernandes:

Em meados da década de 1970, começam a surgir no Brasil, de forma mais intensa em São Paulo e no Rio de Janeiro, equipes teatrais que fazem do projeto coletivo um modo novo de posicionar-se na cultura, na sociedade, na política e na arte. A apropriação conjunta dos meios de produção do teatro, com a cooperativa, a repartição democrática das funções artísticas, a ausência de hierarquias entre os 
criadores, com a consequente diluição dos poderes e dos aparatos repressores implícitos na divisão rígida do trabalho, recuperam, para os jovens artistas independentes, a possibilidade, inusitada na época, de falar em nome próprio, de escolher projetos, de criar textos cênicos de autoria comum, de desprezar "cânones teatrais", de misturar épico, lírico e dramático sem saber que narrar o caso de família, recitar a poesia do amigo ou brigar na cena de namoro era proceder por justaposição de gêneros e fazer teatro contemporâneo (FERNANDES in ARAÚJO; AZEVEDO; TENDLAU (orgs.), 2011, p. 67).

Muitos desses grupos que se formavam podiam ser classificados em duas grandes categorias: os que tinham como cerne principal de seus trabalhos o estético na perspectiva política; e os se opunham totalmente ou, ao menos, evitavam adotar em seus trabalhos posturas explicitamente de cunho político e dedicavam-se mais à chamada "pesquisa de linguagem" (FERNANDES, 2000; GARCIA, 2004).

É importante ressaltar que, embora o posicionamento político explícito seja utilizado para classificar em dois grandes conjuntos os grupos surgidos em meados dos anos 1970, muitas características que tinham em comum, relacionadas ao ideal da organização coletiva para o trabalho e à horizontalização da hierarquia, devem ser apreendidas politicamente. Características, essas, marcantes de produção teatral que se disseminou, a partir daquele tempo, ao longo das décadas seguintes na cidade de São Paulo.

Nesse contexto, o resultado estético alcançado nas criações de coletivos que trabalham com essa "forma de produção", passou a refletir a organização para o trabalho de seus integrantes. Aos poucos, a unidade da obra e a imersão do espectador no espetáculo deixam de ser prioridades 
absolutas. Para se congregar as contribuições para a criação dos diversos integrantes da equipe, expedientes épicos e a dramaturgia de cena, que abarcam a narração, a troca de experiências, a convivência de pontos de vista conflitantes, a sobreposição de estilos, a reflexão sobre a realidade política e social, passavam a mostrar-se mais apropriados para estruturarem os trabalhos criados. Da mesma maneira que expedientes do teatro popular, que atuam no sentido de potencializar a acessibilidade do público à obra como o humor, a música, a dança e a utilização de artes circenses, passaram a ocupar cada vez mais espaço, nas ruas e nas salas de espetáculo.

De certa forma, para dar resguardo administrativo e jurídico aos grupos que se se formavam, por indivíduos que se uniam profissionalmente por intermédio da livre iniciativa para o trabalho, foi criada em 1979 à Cooperativa Paulista de Teatro (MATE, 2009 p. 15). Nos anos 1980, segundo Alexandre Mate (2008) esses ideais colaborativos disseminaram-se nas escolas de teatro paulistanas - nas já tracionais à época, como nas que surgiam no período.

No fim da década de 1990, na cidade de São Paulo, foi criado o Arte Contra a Barbárie, que reunia importantes nomes com trajetória de destaque na atividade cênica brasileira com jovens artistas, muitos formadores de novos grupos na cidade de São Paulo, em movimento que denunciou à mercantilização imposta à atividade artística no período, muito em decorrência da predominância da utilização da Lei Federal de Incentivo à Cultura ( $n^{\circ} 8.313$ de 23 de dezembro de 1991) para a obtenção de recursos para as produções artísticas. A Lei Rouanet, como é conhecida, ainda em vigor, permite e estabelece os moldes de deduções do imposto de renda a pagar por parte de patrocinadores de eventos culturais. Assim, ao transferir as decisões de patrocínio artístico aos departamentos de marketing, 
privilegia produções que darão maior visibilidade às marcas das empresas, via de regra, grandes produções, de preferência lideradas por nomes de grande apelo midiático. Eventos que, de certo modo, não comportam expedientes arriscados tanto do ponto de vista estético, como de posicionamentos políticos e sociais e que são capitalizadas por recursos públicos provenientes da renúncia fiscal concedida aos patrocinadores.

No primeiro manifesto do Arte Contra a Barbárie, assinado por Aimar Labaki, Beto Andretta (Grupo Pia Fraus), Carlos Francisco Rodrigues, César Vieira (Teatro Popular União e Olho Vivo - Tuov), Eduardo Tolentino (Grupo Tapa), Fernando Peixoto, Gianni Ratto, Hugo Possolo (Parlapatões Patifes \& Paspalhões), Marco Antonio Rodrigues (Folias d'Arte), Reinaldo Maia (Folias d'Arte), Sérgio de Carvalho (Companhia do Latão), Tadeu de Souza (Associação Comunitária Monte Azul) e Umberto Magnani (COSTA; CARVALHO, 2008, p. 20), destacou-se a importância da criação de políticas públicas de financiamento as grupos de teatro que se propunham a, em atividade continuada, desenvolverem atividades de pesquisa e experimentação teatral. Propunha-se, desse modo, a sintonias entres os mecanismos públicos de financiamento com a "forma de produção" que se consolidava na cidade de São Paulo.

Sob a influência do movimento, em 08 de janeiro de 2002 foi sancionada a Lei 13.279/2002 que instituiu o Programa Municipal de Fomento ao Teatro para a Cidade de São Paulo. O livro Fomento ao teatro: 12 anos, editado por Carlos Antonio Moreira Gomes e Marisabel Lessi de Mello (2014) apresenta números e gráficos expressivos, resumidos aqui: Entre junho de 2002 a julho de 2014 foram 372 projetos contemplados de 135 núcleos artísticos de um total de 2.328 projetos inscritos. Até julho de 2013 realizaram-se 339 espetáculos com 10.342 apresentações, 
desenvolveram-se 1.531 atividades (oficinas, debates, workshops, palestras e apresentações de trabalhos em processo) e houve 93 publicações (livros, jornais, cadernos, fanzines, revistas e folhetins). A publicação da Secretaria Municipal de Cultura também apresenta mapas que atestam a descentralização cultural na cidade proveniente da realização de atividades relacionadas ao fomento em locais periféricos e afastados do centro da metrópole.

Então, a "forma de produção" que faz com que os resultados estéticos alcançados por grupos teatrais sejam reflexos da organização para o trabalho que problematiza coletivamente características específicas de cada um de seus integrantes, consolida-se na cidade. Os mais recentes trabalhos da Cia. Teatro Balagan e da Cia. Livre, caraterizados por levarem ao público um caleidoscópio de procedimentos estéticos que, sobrepostos, harmonizam fruição e reflexão por parte do público, atestam essa consolidação.

\section{REFERÊNCIAS BIBLIOGRÁFICAS}

ARAÚJO, Antônio; AZEVEDO, José Fernando Peixoto de; TENDLAU, Maria (orgs.). Próximo ato: teatro de grupo. São Paulo: Itaú Cultural: 2011. Disponível em http://issuu.com/itaucultural/docs/proximoato Acesso: 28 de novembro de 2015.

CIA. TEATRO BALAGAN. Cabras - cabeças que voam, cabeças que rolam. Programa de espetáculo em construção. São Paulo: Cia. Teatro Balagan, 2015.

CIA. TEATRO BALAGAN. Do inumano ao mais-humano. Cia. Teatro Balagan (site oficial). São Paulo: Cia. Teatro Balagan, [20--?]a. Disponível em 
http://www.ciateatrobalagan.com.br/pesquisas/do-inumano-ao-maishumano/ Acesso: 25 de novembro de 2015.

CIA. TEATRO BALAgAN. Prometheus - a tragédia do fogo. Cia. Teatro Balagan (site oficial). São Paulo: Cia. Teatro Balagan, [20--?]b. Disponível em http://www.ciateatrobalagan.com.br/espetaculos/prometheus-a-tragediado-fogo/ Acesso: 25 de novembro de 2015.

COSTA, Iná Camargo; CARVALHO, Dorberto. A luta dos grupos teatrais de São Paulo por políticas públicas para a cultura: os cinco primeiros anos da Lei de Fomento. São Paulo: Cooperativa Paulista de Teatro, 2008.

COHEN, Renato. Performance como linguagem: criação de um tempoespaço de representação. São Paulo: Perspectiva; Editora da Universidade de São Paulo, 1989.

FERNANDES, Sílvia. Grupos de teatro nos anos 1970. In: ARAÚJO, Antônio; AZEVEDO, José Fernando; TENDLAU, Maria (orgs.). Próximo ato: teatro de grupo. São Paulo: Itaú Cultural, 2011. p. 66-69. Disponível em https://issuu.com/itaucultural/docs/proximoato/69 Acesso em 28 de novembro de 2015 .

FERNANDES, Sílvia. Grupos teatrais - anos 70. Campinas: Editora da Unicamp, 2000.

GARCIA, Silvana. Teatro da militância: a intenção do popular no engajamento político. $2^{\mathrm{a}}$ ed. São Paulo: Editora Perspectiva, 2004.

GASPARI, Elio. A ditatura derrotada. $2^{\mathrm{a}}$ ed. Rio de Janeiro: Intrínseca, 2014a. A ditadura encurralada. $2^{a}$ ed. Rio de Janeiro: Intrínseca, 2014b.

GOMES, Carlos Antonio Moreira; MELLO, Marisabel Lessi de (orgs.). Fomento ao teatro: 12 anos. São Paulo: Secretaria Municipal de Cultura, 2014. 
HOBSBAWM, Eric. Sobre História. São Paulo: Companhia da Letras, 2013. LEHMANN, Hans-Thies. Teatro pós-dramático. São Paulo: Cosac Naify, 2007. MACHADO, Álvaro. A primaveral teatral de São Paulo. Carta Capital, São Paulo, 01-03-2015.

Disponível em http://www.cartacapital.com.br/revista/838/a-primavera-teatral-de-saopaulo-9759.html Acesso: 29 de novembro de 2015.

MATE, Alexandre. A produção teatral paulistana dos anos 1980 r(ab)iscando com faca o chão da história: tempo de contar os (pré)juízos em percursos de andança. São Paulo, 2008. 561 p. Tese de doutorado em História. Faculdade de Filosofia, Letras e Ciências Humanas, Universidade de São Paulo, São Paulo, 2008.

MATE, Alexandre. Trinta anos da Cooperativa Paulista de Teatro - uma história de tantos (ou mais quantos, sempre juntos) trabalhadores fazedores de teatro. São Paulo: Cooperativa Paulista de Teatro, 2009. MONTAIGNE, Michel Eyquem de. Ensaios. Brasília: UnB; Hucitec, 1987. OSTROWER, Fayga. Criatividade e processos de criação. $29^{a}$ ed. Petrópolis: Vozes, 2013.

PERRUSO, Marco Antonio. Em busca do "novo": intelectuais brasileiros e movimentos populares nos anos 1970/80. São Paulo: Annablume, 2009.

PICON-VALLIN, Béatrice. Meierhold. São Paulo: Perspectiva, 2013.

REIS, Daniel Aarão; RIDENTI, Marcelo; MOTTA, Rodrigo Patto Sá (orgs.). A ditadura que mudou o Brasil: 50 anos do golpe de 1964. Rio de Janeiro: Zahar, 2014.

RIDENTI, Marcelo. As oposições à ditatura: resistência e integração. In: REIS, Daniel Aarão; RIDENTI, Marcelo; MOTTA, Rodrigo Patto Sá (orgs.). A ditadura que mudou o Brasil: 50 anos do golpe de 1964. Rio de Janeiro: Zahar, 2014. p. 30-47. 
RIDENTI, Marcelo. Em busca do povo brasileiro: artistas da revolução, do

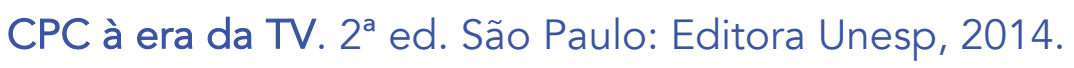

ROMANO, Lúcia (org.). Maria que virou Jonas ou a força da imaginação. São Paulo: Cia. Livre da Cooperativa Paulista de Teatro, 2015.

ROUBINI, Jean-Jacques. A linguagem da encenação teatral. Rio de Janeiro: Jorge Zahar Editor, 1998.

THAIS, Maria. Na cena do Dr. Dapertutto: poética e pedagogia em V. E. Meierhold: 1911 a 1916. São Paulo: Perspectiva; Fapesp, 2009. 
ABSTRACT: From the appreciation of the work of two theater companies from São Paulo: Cia. Livre and Cia. Teatro Balagan, in this article is proposed the concept of "form of production". Concept historically contextualized and determinant for the activity of so-called São Paulo city Theatre Group Movement.

KEYWORDS: Production form; theater group, collaborative creation. 